\title{
Sur en espejo. Portugal en el imaginario curatorial español contemporáneo ${ }^{1}$
}

\author{
CARLOS GARRIDO CASTELLANO
}

University of Lisbons

\begin{abstract}
Resumen
El presente texto analiza la presencia de Portugal en el panorama artístico de la España contemporánea. A través de una revisión de exposiciones y políticas culturales producidas en los últimos veinte años en las regiones de Extremadura y Canarias, se examinará cómo dichos proyectos usan una determinada imagen de lo portugués para negociar la identidad propia en un contexto dominado por la entrada de España y Portugal en la Unión Europea, la regionalización y modernización del país, y la irrupción de un interés por 'el arte de las periferias'. La principal hipótesis que defiende este artículo consiste en afirmar que las relaciones artísticas que tienen lugar en el espacio ibérico resultan imposibles de comprender si no se plantean en un marco mayor, atento a la construcción de identidades y alianzas regionales, pero también a la persistencia en el presente de contradicciones ligadas al pasado colonial e imperial de los territorios ibéricos.
\end{abstract}

\begin{abstract}
This text analyses the presence of Portugal in the artistic panorama of contemporary Spain. Through an examination of art exhibitions and cultural politics in the regions of Extremadura and the Canary Islands, we will study how those projects use a certain image of Portugal to negotiate a singular identity within a framework marked by the inclusion of Spain and Portugal in the European Union, the regionalization and modernization of the Spanish territories, and the development of an interest in 'the art of the peripheries'. The main hypothesis of this article, then, is that the artistic relations in Iberian territory cannot be understood if it is not examined within an international framework, attentive to the configuration of regional identities and alliances, and also to the persistence in our present of many contradictions related to the colonial and imperial past of the Iberian space.
\end{abstract}

1 La investigación que da origen a este artículo ha sido financiada por una ayuda PostDoctoral Fundação Ciência e Tecnologia (FCT) del gobierno portugués. Este trabajo se enmarca dentro del proyecto 'Artistic Curatorship and Difference in the Postcolonial Lusophone and Hispanophone Atlantic Contexts'. (SFRH/BDP/92492/2013). La investigación para este texto fue llevada a cabo en los centros de documentación del Museo Nacional Centro de Arte Reina Sofía, Fundação Calouste Gulbenkian, Centro de Estudos Comparatistas de la Universidade de Lisboa y New York University, instituciones a las que agradecemos su colaboración. Gracias, finalmente, a Santi Pérez Isasi por su lectura atenta y comentarios. 


\section{Sur en espejo. Portugal en el imaginario curatorial español contemporáneo}

Este artículo analiza el papel de Portugal en el proceso de construcción de identidades nacionales y regionales en la España posterior a 1975. Más específicamente, pretende examinar la presencia de Portugal, y en un sentido más preciso, de una imagen 'lusófona' de Portugal, ${ }^{2}$ en la construcción de identidades regionales el panorama artístico y curatorial español posterior a la integración en la Unión Europea. ${ }^{3}$ El interés principal que persigue este trabajo consiste en revisar cómo el arte contemporáneo portugués ha sido presentado en Canarias y Extremadura, dos regiones que han recurrido a configurar una determinada imagen del país lusitano para renegociar una posición propia.

Considerado un momento de acercamiento cultural, económico y político, el periodo que abarca desde mitad de la década de los ochenta hasta el año 2000 aparece dominado por el desarrollo económico y la imbricación con el capitalismo y la modernización de la mano de Europa, ${ }^{4}$ pero también con el replanteamiento de las distintas identidades ibéricas a la luz de la consideración del presente postcolonial de Portugal y España. ${ }^{5}$ El potencial de la comparación de ambos casos subyace, así, en examinar las contradicciones que determinan la articulación de imágenes identitarias en ambos países surgidas a la luz de

2 A lo largo de este artículo el término 'lusófono' aparecerá siempre entre comillas. Con ello se pretende aludir a que dicho término no engloba tanto una realidad nítidamente delimitable, cuanto a una construcción histórico-ideológica que arranca de la noción de luso-tropicalismo y que adquiere connotaciones nuevas a partir de los 70. En el presente, dicho término está vinculado a una voluntad de dar continuidad -si bien camuflados- a sistemas de expresión y ansiedades imperiales en un presente supuestamente postcolonial. Véase Calafate Ribeiro y Ferreira 2003; Vale de Almeida 2000; Ribeiro Sanches 2006. Una perspectiva general de dicho proceso en Tawadros 2005; Maharaj s.d. Véase también los resultados derivados de los proyectos de investigación y creación 'Former West' (disponible en: http://www.formerwest.org/Front [último acceso el 19 de julio de 2016]); 'Curating Europe's Futures' (disponible en: http://www.variant.org.uk/events/cefs/cefs.html [último acceso el 19 de julio de 2016]) y ‘European Museums in an Age of Migration' (MELA) (disponible en: http://www.mela-project.polimi.it [último acceso el 19 de julio de 2016]). Una aproximación teórica acerca de las relaciones entre curaduría artística y cultura en O’Neill 2007, 2012; Barker 1999.

4 Así, Teresa Vilarós (2005) señala cómo la recuperación de la historia tiene lugar en el caso español en un contexto de mercantilización y globalización económica, que implica tanto el fornecimiento (de las lagunas) del archivo histórico nacional como la banalización de las memorias recuperadas. Véase también Gracia García y Ródenas de Moya 2009; Cabañas Bravo 2001; Ramírez y Carrillo 2004. En el mismo sentido cabe entender la alusión de Martí Perán a la espectacularización del arte español de los noventa como un reflejo de 'periplos de postmodernidad tardía'. Consultese http://www.martiperan.net [último acceso el 13 de junio de 2015].

5 La comparación de ambos países a la luz de su pasado colonial y su integración en Europa no es nueva. Por el contrario, aparece con fuerza a inicios de los años noventa, en los debates sobre la posición que Iberia debería ocupar respecto a Europa y respecto a sus 'zonas de expansión', y toma una forma definida en la disputa que Eduardo Lourenço (1994: 83) caracterizaría como 'brandir Gamas contra Colombos', es decir, en los debates sobre las conmemoraciones de Vasco de Gama y de Colón y en la contraposición de las Exposiciones universales de 1992 y de 1998. Una revisión de dichos debates en Sardica 2013, especialmente pp. 283-309. 
la articulación de políticas culturales pretendidamente postcoloniales. ${ }^{6}$ En ese contexto, se pretende examinar cómo las conceptualizaciones de la diferencia y las conexiones y desconexiones que rigen las prácticas culturales ligadas al espacio ibérico obedecen a un juego de alianzas y reflejos que escapa a cualquier oposición totalizadora construida en base a realidades de alcance regional o nacional. ${ }^{7}$ Ello conlleva concebir las imágenes que configuran el imaginario de representaciones y visiones de los territorios ibéricos como resultado de interacciones producidas entre comunidades cuya posición resulta imposible de ser fijada y adscrita dentro de marcos referenciales binarios, tales como centroperiferia o Sur-Norte, o de lecturas homogeneizadoras del nacionalismo portugués y español.

Es preciso, no obstante, señalar desde un primer momento que la presencia del arte contemporáneo portugués en el panorama expositivo español resultará cuantitativamente mucho menos significativa que, por ejemplo, la del arte latinoamericano, el principal referente artístico externo 'incorporado' por la España post-Dictadura. ${ }^{8}$ En ningún caso pretende este artículo valorar una conexión a menudo excluida de los debates acerca de las coordenadas geográficas que rigen el arte español post-dictadura. Pese a la existencia de momentos de acercamiento, las exposiciones de artistas portugueses y las colaboraciones entre ambos países seguirían siendo escasas. Dicho de otro modo: tanto España como Portugal reformularon su identidad artística de espaldas al país vecino, a

6 Entendemos dicha condición postcolonial no en términos literales/ cronológicos, es decir, como una pertenencia a un tiempo 'post', sino más bien como una situación en la que diversos problemas ligados a la naturaleza colonial de los territorios portugués y español se manifiestan en el presente de forma no lineal y conflictiva. En ese sentido, lo postcolonial nunca referirá a un estado de cosas previamente dado, sino a la articulación problemática de situaciones de dominación ligadas a la colonialidad en el pasado y en el presente. Véase los trabajos clásicos de Loomba 2015; Appiah 1991; Bhabha 1994.

7 La problematización del presente postcolonial de España y Portugal se produce, al menos en lo referente a las artes visuales, con retraso con respecto a Gran Bretaña o Francia. Sólo será a inicios de los noventa, en el marco de las conmemoraciones y de la integración en la Unión Europea, cuando encontremos exposiciones y aportaciones teóricas que, desde perspectivas harto diferentes, aborden las contradicciones del proceso de modernización y 'multiculturalización' de ambos países. En España estos pueden estar caracterizados por exposiciones como 'Cocido y Crudo' (MNCARS, 1994), 'Comer o no Comer' (Salamanca, 2003), 'Otro país: Escalas africanas' (CAAM, 1994-1995) o 'Versiones del Sur: Cinco propuestas en torno al arte en América' (MNCARS, 2000-2001). En el caso de Portugal este debate ha sido brillantemente resumido por Antonio Fernandes Dias (2006), e incluiría muestras como 'Looking Both Ways' (Fundação Gulbenkian, 2005), 'Renée Green: Tracing Lusitania' (CCB, 2002), 'Um océano inteiro para nadar' (Culturgest, 2000), 'Lisboa-LuandaMaputo' (Cordoaria Nacional, 2007) o 'Réplica e rebeldia: artistas de Angola, Brasil, Cabo Verde e Moçambique' (Instituto Camões de Lisboa, 2006). A ello hemos de añadir exposiciones más recientes integradas en el programa 'Próximo futuro' de la Fundação Gulbenkian o en la programación de Culturgest.

8 El proceso descrito en la nota anterior tendrá en el caso español a América Latina como su principal objetivo. A la creación de grandes colecciones en los principales museos de arte contemporáneo del país y al protagonismo en numerosas ediciones de ARCO cabe añadir la realización de exposiciones que protagonizarán -con mayor o menor intención crítica- la redefinición identitaria supuestamente postcolonial española. 
través de referentes ligados al pasado colonial e imperial de ambos países. ${ }^{9}$ No se pretende, por tanto, transformar ese mapa a través de una incorporación de ejemplos omitidos que enriquecerían la historia de las relaciones ibéricas; se busca, más bien, cuestionar los términos que rigen la lógica de dichos imaginarios, ubicándolas en un territorio marcado no tanto por fronteras y exclusiones cuanto por encabalgamientos que vinculan de formas heterogéneas pasado y presente.

No obstante, la presencia de Portugal en las políticas curatoriales españolas constituye un punto fundamental a la hora de construir los discursos identitarios regionales y nacional de un país inmerso en un replanteamiento de su propia posición geopolítica con respecto a la Unión Europea. Extremadura y Canarias ofrecen ejemplos paradigmáticos de las contradicciones presentes en las definiciones 'culturalistas' de una identidad nacional: ambas se encuentran alejadas cultural y económicamente del panorama de pretendida integración con Europa y expansión internacional que los gobiernos socialista y conservador esbozan respectivamente desde mitad de los ochenta hasta finales de los noventa, buscando otorgar a España una posición de preeminencia en las configuraciones geopolíticas del momento (véase Aliaga 2005). En ambas regiones, por tanto, la distancia con el 'centro' representado por Madrid se plasmará en la búsqueda de un elemento de comparación que permitiera una definición de la propia identidad y en la articulación de políticas culturales que singularicen la posición que tanto Canarias como Extremadura ocupan en la realidad española contemporánea. Existirá, por tanto, una voluntad de reposicionar la pertenencia de Extremadura y de Canarias a un marco atlántico que se hace coincidir con la idea de Sur, ${ }^{10}$ y en ese proyecto la presencia de Portugal resultará fundamental.

Este artículo se plantea dos objetivos. En primer lugar, se busca emplazar las representaciones artísticas de Portugal exhibidas en el ámbito español en un marco espacial que va más allá del nacionalismo, pero que también atiende a las continuidades y discontinuidades de la colonialidad y de los sistemas de othering que están en juego en la Europa post-Muro. En segundo lugar, trataremos de complicar el mapa curatorial y cultural de la hispanidad y de la 'lusofonía' a través de una conceptualización de las relaciones identitarias portuguesas y españolas como una realidad multicéntrica, que escapa a las fronteras nacionales de ambos países y articula en el presente múltiples realidades espaciales, no exentas de contradicciones.

9 Véase, para el caso portugués, Rosengarten 1998; Fernandes Dias 2006. La principal referencia para el caso español sigue siendo la colección de volúmenes publicados en la revista Desacuerdos. Sobre arte, políticas y esfera pública en el Estado español (disponible en http://caam. net/es/pdf/proyecto.pdf [último acceso el 8 de agosto de 2016]); (véase Vilarós 2005).

10 En palabras de Roberto Vecchi (2013: 71): 'Iberia therefore always provokes a reconfiguration of the idea of the (European) south in relation with other "South(s)"'. Resultará necesario, en cualquier caso, entender esa reconfiguración no tanto como un estado de cosas sino como un proceso activo en el que intervienen múltiples fuerzas. 


\section{Una vía curatorial a la modernidad}

Las exposiciones examinadas permiten observar de manera crítica la articulación entre identidades regionales y nacionales y aspiraciones cosmopolitas; entre la democratización de la cultura y su mercantilización; y, finalmente, entre la percepción propia y ajena de dichas identidades en la España post-dictadura. En las últimas décadas del siglo XX se desarrolla en España una política cultural que intenta definir, de la mano de nuevas instituciones (véase Holo 1999), los elementos que servirían para negociar la posición del país dentro del marco europeo. ${ }^{11}$ La creación de instituciones culturales forma parte del intento de definición de una España democrática y cosmopolita tras el encerramiento representado por la dictadura franquista. Los museos creados a lo largo de los noventa deberían cumplir la función de dinamizadores urbanos y agentes de modernización repartidos por todo el territorio peninsular; al mismo tiempo, serían concebidos como marca identitaria de cada región o comunidad, estableciendo así una suerte de competencia entre estas.

En España, el giro curatorial viene, por tanto, de la mano del desarrollo de nuevas instituciones y de un interés por convertir al arte contemporáneo en un recurso turístico y patrimonial. Gran parte de los nuevos centros fueron concebidos como agentes de modernización y desarrollo urbano, convirtiéndose en muchos casos en el emblema de ciudades que, de la mano de éstos, volvían a formar parte de los itinerarios turísticos y culturales nacionales (véase Esteban 2007). Los últimos años de los ochenta y la primera mitad de los noventa marcan el momento clave de ese desarrollo. El Museo Nacional Centro de Arte Reina Sofía se crea en 1992, una fecha llena de simbolismo debido a la conmemoración del Quinto Centenario del 'Descubrimiento' de América; el Museu d’Art Contemporani de Barcelona (MACBA) se funda en 1995, y dos años más tarde lo hará el Guggenheim de Bilbao. A la cimentación de un tejido institucional precedería, en cualquier caso, la voluntad de estructurar un mercado de arte y una red de coleccionistas inexistente hasta el momento. Dentro de ese contexto cabe situar asimismo la creación de ARCO en 1982.

Como se verá a continuación, las exposiciones y proyectos que este artículo analiza surgen en el marco anteriormente descrito, dominado por el desarrollo institucional ligado a la configuración de entidades autonómicas, así como por el proceso -contradictorio- de construcción de una imagen de la modernidad ligada al arte contemporáneo.

\section{'Sur' en espejo. Portugal en las políticas curatoriales extremeñas y canarias}

Las instituciones y los planteamientos curatoriales que se examinarán a continuación están caracterizados por proyectar una serie de valores en un referente común, Portugal. Tanto en el caso extremeño como en el canario, existe un mismo

11 Un proceso de redefinición identitaria estaba teniendo lugar al mismo tiempo bajo diversas formas en el continente europeo Post-Muro. Véase Chambers et al. 2014; Whitehead et al. 2015; Basso Peressut, Lanz y Postiglione 2013. 
interés por definir identidades culturales ligadas a la idea de 'Sur', y por vincular dichas identidades de forma relacional con otros territorios igualmente considerados ajenos a las dinámicas de una 'modernidad canónica'. Dicho posicionamiento se presenta a veces como resultado de uniones naturales, evidentes. Sin embargo, como veremos a continuación, tanto la condición de 'Sur', proyectada en Portugal y presente en los discursos curatoriales que se analizan, como el elemento moderno al que dicha condición busca contraponerse, se muestran como realidades porosas, difíciles de definir y en última instancia problemáticas.

\section{'O próprio da arte é o não conhecer fronteiras'}

Desde su fundación en 1994, el Museo Extremeño e Iberoamericano de Arte Contemporáneo (MEIAC) pretendió restablecer la función de puente entre España, Portugal y América Latina que teóricamente Extremadura siempre había desempeñado. La situación fronteriza de Badajoz la convertía en el centro ideal de ese triángulo, al tiempo que le permitía engancharse desde una posición singular al carro de centros de arte españoles fundados en los noventa. Ese panorama, configurado ex novo, pretendía enfrentar la triple problemática de integrar 'el arte de las periferias' en una España que estaba revisando su propia imagen a la luz del 'efecto Sevilla', ${ }^{12}$ configurar una red cultural y comercial para la actividad cultural inexistente hasta el momento, y, finalmente, hacer del arte contemporáneo un recurso más de la imagen española en Europa (Carrillo y Noriega 2004: 11).

Cuando Bernardo Pinto de Almeida afirma con respecto a los inicios de la modernidad artística portuguesa durante el Salazarismo que 'Tudo foi mais pequeno, mais modesto, mais convivial, com as consequências que teve, ou não chegou a ter' (1995: 181), bien pudiera estar aludiendo a otras dos realidades: la de determinados escenarios regionales dentro del ámbito hispánico, y la del propio caso español dentro de Europa. Pinto de Almeida presenta un panorama en el que el ensimismamiento de la dictadura, en el que 'a arte portuguesa viveu mais dominada por uma situação interna de pequenos equívocos [...] do que deixando-se penetrar por uma capacidade de afirmação própia que a distinguisse' (1995: 181), termina tras la dictadura en 'uma nova situação, nomeadamente no que tocava às relações com a cultura europeia' (1995: 186). No obstante, ese proceso, que acontecería en ambos países al mismo tiempo, se producía de manera independiente.

El MEIAC venía a remediar esa situación, de la mano de la recuperación de una tradición de encuentros y cultura fronteriza que podría remontarse siglos atrás. Resulta elocuente que la descripción de la evolución histórica del arte

12 El impacto de la Exposición Universal de 1992, realizada en Sevilla, se plasmaría en la capital hispalense a través de una reforma urbanística radical, que transformaría completamente la ciudad. Para una revisión del papel de las exposiciones y las industrias culturales en la transformación urbanística en España, véase Renau 2010; Monclús Fraga 2006. Para una perspectiva intercontinental de dicho proceso véase Viala 2014. 
portugués hecha por Pinto de Almeida sea parte del texto fundacional del propio museo extremeño: rompiendo con una trayectoria de desconexiones e ignorancia mutua, la creación del MEIAC abría un nuevo momento para el arte portugués de la mano de ideales iberistas. Al final del texto de Pinto de Almeida citado anteriormente, el historiador y crítico de arte portugués se muestra esperanzado de cara al futuro:

Que o gesto inaugural desse reconhecimento (não tanto por ser o primeiro caso de instituição que se abre à arte portuguesa mas claramente por ser a primeira vez que tal se faz de modo sistemático pela constituição de uma coleç̧ão) nos chegue de Espanha, e em particular de uma cidade fronteiriça como Badajoz de larga tradição de relação com Portugal, só vem demonstrar a pertinência daquilo que os apologistas de um reforço do eixo ibérico há muito defendiam: que a proximidade dos dois países não pode ser apenas geográfica mas que se reencontra numa dimensão cultural que historicamente se justifica por quanto aproximou mais nobremente os dois países no decorrer dos últimos séculos e que somente a cegueira de alguns, ciosos de ressentimentos nacionalistas extremados e atávicos no seu anacronismo pretendem ignorar. Tanto mais que o próprio da arte é o não conhecer fronteiras... (Pinto de Almeida 1995: 192)

En términos curatoriales, la voluntad de integración se produjo mediante la creación de diferentes modelos de exposición. En primer lugar, desde su fundación el MEIAC generó iniciativas transfronterizas y exposiciones individuales de artistas portugueses (João Jacinto, Helena Almeida, Julião Sarmento). Buen ejemplo de ello es 'Além da Água: Copiacabana', un proyecto co-curado por Mar Villaespesa y Jorge Castanho en 1996. Ubicado en la frontera entre Extremadura y el Alentejo, el proyecto exploró las relaciones entre Portugal y España en el contexto de la construcción de una presa en el Río Guadiana a inicios de los noventa. Dicho proyecto hidráulico se mostraba problemático en varios sentidos: primero, por poder dar lugar a situaciones de desigualdad en el reparto del agua, que derivaban en una reflexión más amplia sobre la desigualdad económica de ambos países; segundo, por la inserción de ese debate en el contexto de la demanda de fondos europeos para paliar la sequía y 'fomentar el desarrollo' del territorio peninsular (Villafranca 1998). La exposición, pues, reflexionaba sobre la relación de vecindad de ambos territorios tras la abolición de la frontera en el marco europeo, utilizando el fluir del agua para aludir a la potencialidad de los intercambios artísticos (Villafranca 1998: 125). Pese a la intención de crear un proyecto binacional unificado, la exposición se fragmentaría en dos vertientes: la portuguesa, curada por Jorge Castanho, consistente en una serie de intervenciones site-specific en poblaciones alentejanas, y la española, consistente en una muestra centrada en torno al agua y a las fronteras presentada en el MEIAC que contaría con la colaboración de artistas y público internacional, y en la que el visitante podía también adicionar material que sería incluido en el display general.

Entre las intervenciones de 'Além da Água: Copiacabana' predominaría un tono de indagación en el contexto específico de las poblaciones donde las obras 
tendrían lugar, con especial atención a cuestiones ecológicas. La aproximación a la situación actual del territorio que baña el Guadiana serviría para hablar de los peligros de la contaminación ambiental, de las fronteras o de la piratería; sin embargo, aunque la propia muestra surge como intento de acercar regiones 'con historias imperiales compartidas' (Villafranca 1998: 123), lo global aparecería como una realidad o una fuerza abstracta, desligada de las consecuencias de esa historia imperial.

'Além da Água' preludiaría la que ha sido la exposición más ambiciosa sobre la relación entre ambos países y sobre el iberismo: 'Suroeste. Relaciones literarias y artísticas entre Portugal y España 1890-1936', una muestra organizada en 2010. 'Suroeste' esbozaba una reflexión acerca de la noción de vanguardia a través del acercamiento a las décadas cumbres del iberismo. Considerando que 'españoles y portugueses provocaron con frecuencia proyectos y colaboraciones comunes como una vía valiente y genuina para luchar contra cierto aislamiento cultural' (Sáez Delgado y Gaspar 2010: 13), la exposición presentaría documentos históricos, obras artísticas y cartas de personalidades del momento. Igualmente, de la muestra se derivaría un ambicioso catálogo bilingüe. En 'Suroeste' la configuración de identidades aparece cimentada a través de las obras y materiales recuperados, lo que la convierte en el ejemplo curatorial de arte portugués en territorio español mejor organizado y justificado.

Un segundo bloque de muestras estaría caracterizado por los 'Diálogos', encuentros entre artistas extremeños, por un lado, y creadores portugueses y latinoamericanos, por otro. Así, la producción de Pérez Villalta sería confrontada con la de Pedro Proença; la de Andrés Serrano con la de Leonel Moura; o la de Florentino Díaz con la de Carlos Capelán. Finalmente, el MEIAC importaría muestras monográficas y grupales de arte portugués, colaborando con centros portugueses, colecciones privadas y con instituciones como el Gabinete de Iniciativas Transfronterizas.

\section{La suma de todos los particularismos}

En Canarias encontramos un similar interés por definir una identidad propia en el momento democrático. En esta ocasión, el referente ineludible será la pertenencia al Atlántico y el valor de 'puente entre dos mundos' del archipiélago, un valor presente en las representaciones de Canarias desde el siglo XVIII hasta el final de la dictadura. Tras el Franquismo, no obstante, la formulación de Canarias como el 'fin de Europa y el comienzo del Atlántico' -una posición cercana a la visión de Portugal como 'o lugar e o momento onde a Europa das Nações acaba e o Mundo dos Impérios começa' (Clara 2006: 282)- da paso a la noción de tricontinentalidad, que hace de Canarias el referente central de los 'intercambios' entre Europa, África y América. ${ }^{13} \mathrm{El}$ principal valedor de la idea

13 En el terreno del arte, el principal promotor de valores identitarios tricontinentales será el Centro Atlántico de Arte Moderno (CAAM), situado en Las Palmas de Gran Canaria, fundado en 1989. 
de tricontinentalidad será el Centro Atlántico de Arte Moderno (CAAM), creado en Las Palmas de Gran Canaria en 1989. Descrita como 'inicio de la transculturalidad y la globalización contemporáneos, ${ }^{14}$ la tricontinentalidad surge en el contexto preciso de la España de las Autonomías integrada en la Unión Europea, un momento en el que Canarias queda ubicada en la categoría de región ultraperiférica de la nueva entidad continental. ${ }^{15}$

Pese a la importancia del referente a la tricontinentalidad en la definición de una identidad canaria, en este caso la colaboración con artistas caboverdianos, madeirenses y azorianos será mucho menos frecuente que la articulación de vínculos entre Extremadura y Portugal 'continental'; sin embargo, ésta resultará relevante al ofrecer la posibilidad de aludir a una identidad macaronésica que haga más 'concreta' las aspiraciones implícitas en el concepto de tricontinentalidad. Los contactos con Madeira, Azores y Cabo Verde suponen, en este caso, la continuación de una política curatorial centrada en contextos insulares, en el ámbito atlántico y en África. ${ }^{16}$ Así ocurre, por ejemplo, en 'Horizontes insulares', un ambicioso proyecto artístico-literario itinerante creado en 2010 y comisariado por Orlando Britto Jinorio y Nilo Palenzuela. ${ }^{17}$ Ambos ya habían dirigido en 1997 'Islas', una exposición que reunió a creadores y teóricos de contextos insulares de todos los continentes; el propio Britto trabajaría como curador y conservador en el CAAM durante gran parte de la década de los noventa.

'Horizontes Insulares' continuaba la idea de 'Islas', una exposición centrada en la expresión artística de la identidad insular en varios continentes organizada por Britto y Palenzuela en 1997. Sin embargo, el foco global de 'Islas' era trasladado en este caso al horizonte macaronésico. El proyecto invitaba a doce artistas a cuestionar la insularidad, teniendo al mismo tiempo por objetivos la creación de lazos entre sus regiones. Artistas y teóricos 'lusófonos' (Maria José Cavaco, Tchalé Figueira, Ricardo Barbeito, Irineu Rocha, Assunção Melo e Isabel Santa Clara) darían réplica a las insularidades 'hispanas', representadas por Canarias, Puerto Rico, Cuba y República Dominicana, y francesas (Reunión, Guyana, Martinica y Guadalupe). La selección territorial cumpliría, entonces, el doble objetivo de conectar 'las ya antaño "periferias de Occidente"' (Britto Jinnorio y Palenzuela 2010: 40) y de pensar su estatus como territorios periféricos de la Unión

14 Véase http://caam.net/es/pdf/proyecto.pdf

15 Las regiones ultraperiféricas de la Unión Europea comprenden territorios pertenecientes a España, Portugal y Francia y situados en el Atlántico, en el Índico y en el Caribe. Se trata de Canarias, Azores y Madeira en el Atlántico; Guadalupe, Martinica, Guyana Francesa y San Martín en el Caribe; y Reunión y Mayotte en el Índico.

16 Sirvan de ejemplo la exposición original del CAAM, 'Surrealismo entre Viejo y Nuevo Mundo' (1989-1990), que contaría con una importante representación canaria y caribeña; 'Desplazamientos. Aspectos de la identidad y las culturas' (1991); 'África Hoy' (1991); 'Voces de Ultramar: Arte en América Latina y Canarias: 1910-1960' (1992); 'Otro país. Escalas africanas' (1994-1995).

17 El hecho de que el proyecto expositivo fuera presentado también en varios territorios atlánticos y caribeños (Madeira, República Dominicana, Cuba y Martinica) con los cuales la muestra plantea una relación geográfica-cultural, constituye uno de los puntos fuertes del proyecto y supone una excepción en el ámbito curatorial español. 
Europea. La exploración de la creatividad producida en regiones ultraperiféricas había tenido algunos episodios de interés en Francia, donde surgiría asociada a cierta idea de la créolité entendida como definidora de un modelo de ciudadanía global no siempre bien separado de cierto 'imperialismo cultural' francófono. ${ }^{18}$ 'Horizontes Insulares' se desvincularía de esa idea, en la creencia de que existen puntos de unión entre los espacios abordados con independencia a la lengua y a la pertenencia a zonas de influencia distintas. Al mismo tiempo, mantendría el interés por explorar la creatividad producida en contextos insulares (todos los artistas integrados en la muestra residen en su territorio de origen).

Hemos de señalar, en cualquier caso, que los vínculos que plantea la exposición no son nuevos; por el contrario, la conexión con el Caribe y con África formaba ya parte de las políticas culturales tricontinentales y subalternas que el CAAM llevaba a cabo desde principios de los noventa. La novedad del horizonte planteado por la muestra reside, en cambio en su intento de articular un proyecto itinerante que arranca en la ciudad más grande situada en las regiones ultraperiféricas de la Unión Europea y que salvo por la inclusión del Caribe hispano se solapa con el mapa de dichas regiones. Uno de los aspectos más interesantes de Horizontes Insulares vendría representado por la faceta de investigación y de colaboración transnacional que llevaría a cabo. Esa línea confluiría con las exposiciones y eventos desarrollados por Casa de África, una organización de carácter nacional con sede en Las Palmas creada en 2007 con el objetivo de 'estrechar las relaciones culturales entre España y África’. Dentro de la actividad más reciente de Casa de África encontramos dos exposiciones 'lusófonas': 'Escena Caboverdiana', una muestra curada por Orlando Britto que contaría con la participación de Irineu Rocha, Tchalé Figueira y Leão Lopes; y 'La modernidad ignorada. Arquitectura moderna de Luanda', resultado de un proyecto de investigación dirigido por la Universidad de Alcalá de Henares en colaboración con centros portugueses y angolanos.

\section{Políticas culturales para modernidades excéntricas}

En los dos casos examinados, los discursos curatoriales que implican un acercamiento a Portugal se justifican por razones de proximidad histórica. Sin embargo, la presencia de Portugal, presentada a partir de la 'unión natural' e histórica de Extremadura y Canarias con Portugal serviría no sólo para dar a conocer una realidad artística en cierto modo ausente dentro del resto del panorama nacional español; al mismo tiempo, permitiría a estas regiones generar una imagen propia de sí mismas, singularizándolas y desmarcándolas de la masa nacional y posibilitando una distinción en las políticas culturales españolas. La incorporación de Portugal a los imaginarios curatoriales y culturales extremeño y canario se

18 En esta línea podemos mencionar el caso de 'Látitudes', un megalómano proyecto que por espacio de siete años abarcaría varios territorios 'vinculados a la cultura francesa', en muchos casos coincidentes con regiones que todavía hoy mantienen un vínculo de subordinación política con respecto a Francia. 
produce, como hemos visto, en función de necesidades y de discursos diferentes. En ambos casos, sin embargo, el arte portugués es utilizado para justificar una pertenencia al ámbito atlántico. Los valores asociados a esa pertenencia, y la justificación que permite erigir una identidad en torno a ellos, serán diferentes en cada uno de los dos contextos.

En el caso de Extremadura encontraremos una posición cimentada frente al centralismo madrileño, identificado a partir de la ignorancia de 'las periferias peninsulares, ${ }^{19}$ y por una sumisión a los flujos del mercado vinculados de manera difusa a Europa (véase Franco Domínguez 1995). El MEIAC, en ese contexto, ofrece una vía alternativa, 'iberoamericana', marcada por su condición fronteriza, pero sobre todo por la vocación latinoamericanista del museo. Esa vía alternativa se materializaría a partir de la organización de exposiciones ligadas a América Latina y a Portugal (resulta significativo que el número de muestras de artistas portugueses resultara mayor al de exposiciones de artistas 'del resto de España' (Godoy 2011)), de la conformación de una colección de arte portugués, extremeño y latinoamericano, ${ }^{20} \mathrm{y}$ de la promoción de debates críticos sobre arte y globalización (véase Mosquera 2004). Portugal era, en ese marco, una realidad 'esencial, inevitable' (Logroño 1995), un vínculo olvidado por las pretensiones modernizadoras que teñían desde Madrid al arte español contemporáneo, que convertía a Badajoz en un centro ibérico con proyección atlántica (Godoy 2011). Precisamente, la proximidad con Portugal servirá para constituir un nuevo centro con clara vocación oceánica, que por fin lograba conectar al arte extremeño, sujeto a un fenómeno de aislamiento similar al que Pinto de Almeida dibujara para el caso portugués, con la versión más 'postcolonial' de la globalización. No deja de ser significativo el hecho de que la inserción del arte extremeño en España, la apertura a América y la creación de un nuevo faro iberoamericano, y la proximidad esencial con Portugal, sean presentados como parte de una misma jugada que, por lo demás, es presentada como algo natural, lógico, en última instancia una simple reactualización de la Extremadura de los Conquistadores y de la frontera porosa con Portugal (Godoy 2011).

Algo similar ocurre con el caso canario, donde la singularidad regional también aparecerá justificada por la pertenencia al Atlántico. La originalidad de los discursos sobre la tricontinentalidad será justificada desde una posición de puente, es decir, de trampolín en la conquista española de América, hacia una realidad marcada por la confluencia [Sic!] multidireccional de lo africano, lo europeo y lo americano, cuyo objetivo quedaría resumido en una visión de la

19 En palabras de Miguel Logroño (1995: 250): ‘¿Es el arte Madrid por su condición axial, de kilómetro cero, o de esa cosa cursi de crisol de todas las Españas?'.

20 El análisis del coleccionismo en la España de la democracia y del 'multiculturalismo' todavía está por hacerse. Si bien en este caso nos centraremos únicamente en el análisis de las exposiciones, no podemos dejar de percibir que el tamaño y el criterio de la colección de arte portugués que posee el MEIAC, centrada sobre todo en artistas nacidos entre los cincuenta y los setenta (Ângela Ferreira, Julião Sarmento, Pedro Cabrita Reis, Rui Sanches, Fernanda Fragateiro, Paulo Mendes) y representantes de la versión más 'internacional' del arte portugués, ofrecen un más que interesante objeto de análisis. 
universalidad concebida como 'la suma de todos los particularismos' (Njami 1999: 22). En ello hay un intento decidido de singularizar la identidad propia dentro de España y de Europa, y de pensarla desde la originalidad de una posición ligada al Sur, que permitiría, en lo que al arte se refiere, 'vulnerar la lógica de los circuitos artísticos predeterminados y hegemónicos abriendo circuitos artísticos alternativos, desde un auténtico diálogo simétrico, posibilitando en un eficiente proceso la incorporación de otros agentes, otra mirada crítica, otro acervo simbólico al concierto global del arte' (CAAM s. d.).

Es importante tener en cuenta, en cualquier caso, que la construcción de identidades regionales es presentada en ambos casos no sólo como una alternativa al centralismo y al 'europeísmo' supuestamente representado por Madrid; al mismo tiempo, supone la asunción de un tipo de modernidad excéntrica, diferente, a la opción que presenta la integración europea. Las exposiciones de arte portugués y 'lusófono' no reclaman, por tanto, una identidad regional, aislada de la globalización. Por el contrario, mediante la articulación de lazos culturales con otros espacios, se presentan como una versión más adecuada, más avanzada, más 'auténtica', de la modernidad.

\section{¿'Sures' curatoriales?}

La idoneidad de Portugal como referente en la construcción de identidades culturales en Extremadura y Canarias resulta en gran medida del intento de equiparar la situación 'periférica' de ambas regiones con la propia singularidad del país luso en el escenario europeo. En trabajos ya clásicos, Boaventura de Sousa Santos definió Portugal como una 'semi-periferia', como un espacio intermedio (1994; 2002). De acuerdo con este planteamiento, la posición excéntrica de Portugal dentro de Europa y dentro de los repartos imperiales la convierte en un potencial ejemplo anti-hegemónico. Si bien no mencionado directamente, la recuperación de Portugal y de su 'proyección atlántica' llevada a cabo a través de las exposiciones que aquí hemos analizado se encuentra claramente en sintonía con las ideas del sociólogo portugués.

¿Debemos, así pues, considerar la presencia portuguesa en el imaginario curatorial extremeño y canario como un ejemplo de sintonía justificada por la pertenencia común al 'Sur', como ejemplo de vínculos culturales South-South? Por un lado, debemos constatar que las políticas curatoriales de las dos regiones analizadas ofrecen el ejemplo más claro en el ámbito español de interés por conectar producciones artísticas locales con la redefinición 'postcolonial' de España y con 'el arte de las periferias'. Debemos, sin embargo, ser cautos, modificando la pregunta anterior y cuestionando qué función desempeñan dichos vínculos.

En ese sentido, podemos constatar cómo la 'vocación atlántica' y la proyección hacia el 'Sur' de ambos contextos funcionó siempre como parte de un sistema de marginalizaciones y subalternidades complejas, elaboradas en ocasiones contra un referente nacional, en otras en relación a Europa, y finalmente en otras a 
través de vínculos con territorios que comparten el estatus de 'periferia'. La conexión con el 'Sur' representado por Portugal ha de ser vista, entonces, menos como una simple localización y más como el resultado de políticas culturales precisas. En palabras de Roberto Vecchi: 'Rather than simply locating itself [...], the South is constituted as a clash of powers, a concentration of force and social violence that always keeps the continent in its background' (2013: 78).

Si aceptamos la idea de Boaventura de Sousa Santos (2002) de que Portugal constituye un 'Third Space' en el ámbito atlántico, si ubicamos el imaginario de lo portugués, junto con las alianzas y representaciones (equivocadas o no, precisas o no) que lo componen, en un contexto de semi-periferia, la conexión con otros espacios intermedios, periféricos e híbridos se mostrará como algo natural, espontáneo. Como hemos visto, los discursos que justifican la presencia de Portugal en el imaginario curatorial español responden a intereses y posicionamientos concretos $y$, por consiguiente, no pueden ser consideradas en ningún caso como algo natural. En nuestro caso de estudio, hablar de hibridismo supondría establecer una conexión en función de privilegiar el binomio centroperiferia, condenando a esos 'lugares semiperiféricos' a tener unos interlocutores fijos. Lejos de considerar el tráfico de representaciones que evidencian las exposiciones aquí analizadas un ejemplo del interés de dos territorios españoles 'subalternos' en la condición 'semi-periférica' de Portugal, consideramos que los discursos curatoriales analizados han de ser confrontados dentro de un sistema más complejo, que deberá mostrarse atento a negociaciones regionales de la identidad que sobrepasan la relación entre nacionalismos portugués y español, pero también a la colonialidad del propio proceso de modificación espacial de la Europa post-Muro.

\section{Vecindad y colonialidad}

Las exposiciones que he analizado aquí se acercan al arte portugués y 'lusófono' en virtud de una reactualización de vínculos históricos y de una expresión de una posición singular compartida. Sin embargo, dichas exposiciones forman parte no sólo de imaginarios regionales constituidos a partir de una vecindad geográfica con Portugal. A su vez, constituyen elementos centrales de los discursos culturales que desde varias partes del territorio ibérico se acercan a la colonialidad de Portugal y España (Vecchi 2013). Los proyectos analizados muestran cómo los elementos identitarios 'ibéricos' relacionados en el ámbito de la Península y las islas Atlánticas surgen sujetos a las contradicciones entre diversas conceptualizaciones y articulaciones de identidades nacionales, por un lado, e imperiales por otro, que se solapan de maneras conflictivas y transitorias. Estas cuestiones han sido recientemente planteadas tanto en Portugal como en España. ${ }^{21}$ De

21 En ese sentido podemos considerar el siguiente cuestionamiento: 'there are still many questions that need to be answered. For instance, how do these studies of Iberian literatures deal with its insularities, or with what in earlier times were Iberian colonies, including Latin America or the Lusophone world? Is this Iberian division strong enough 
hecho, si algo ha caracterizado al debate crítico sobre las relaciones culturales en el ámbito ibérico ha sido la necesidad de conectar la formación de identidades nacionales y regionales con otros nacionalismos en el ámbito europeo (véase Buffery, Davis y Hooper 2007; Epps y Fernández Cifuentes 2005). Sin embargo, las aproximaciones 'postcoloniales' a ambos contextos suelen considerarse de manera independiente, valorando únicamente la relación de cada país con el espacio ligado a sus antiguas colonias. Creemos que la valoración crítica de proyectos curatoriales peninsulares ofrece un campo de análisis igualmente fecundo a la hora de abordar las contradicciones de los territorios ibéricos en la actualidad.

Los discursos curatoriales regionales que he analizado no siempre consiguen articular de forma satisfactoria dicho vínculo. Existe, en otras palabras, una distancia insalvable entre la intención de reclamar una posición alternativa, especialmente transnacional y 'postcolonial' con respecto a las políticas culturales españolas, y la realidad presente de Extremadura y Canarias. En el caso del MEIAC, las políticas culturales ligadas al arte contemporáneo se configuran a partir de un diálogo tripartito que pretende escapar del europeísmo y del centralismo que representaría Madrid, y que vendría a estar representado por la inmersión en el capitalismo vía Europa y por el olvido de Portugal. Frente a ese modelo, América y Portugal aparecerían como interlocutores naturales de una Extremadura que ejemplificaría una vía alternativa a la modernidad. Como hemos visto, las políticas curatoriales 'transfronterizas' implican el reconocimiento de una Portugal inmersa en un mismo proceso de 'modernización alternativa' que, pese a todo, no implica un replanteamiento de su 'portugalidad'.

Por su parte, proyectos como 'Horizontes Insulares' muestran cómo en Canarias el arte contemporáneo juega asimismo un papel decisivo en la producción de identidades y en la construcción de un contexto que comparte varias conceptualizaciones espaciales -entre ellas la nacional, la Europea, la 'Atlántica', la 'macaronésica', la 'Tricontinental'. Sin embargo, la asimilación del territorio canario y macaronésico con un imaginario transnacional atlántico no está exenta de problemas. En cierto modo, la conexión con espacios como el Caribe se consigue únicamente al aceptar lo insular como sinónimo de procesos de creolización, como espacios 'singulares' de intercambio cultural y racial. Dichos procesos, que forman parte de la historia y de los debates teóricos caribeños, ${ }^{22}$ resultan mucho más difícilmente aplicables al caso canario. En ambos casos, pues, la relación vecindad-colonialidad, ligada a la incorporación de Portugal a los discursos curatoriales regionales, se muestra cuanto menos problemática y abierta a un análisis crítico.

to justify the exclusion of Basque literature written in Iparralde, the French part of the Basque Country? How about Latin, Arab or Hebrew writers in the Peninsula? Are writers from modern-day Gibraltar British, Iberian, or both?' (Pérez Isasi 2013: 22).

22 Una valoración acerca de la fortuna crítica de la creolización en la teoría crítica caribeña en Crichlow y Northover 2009. 


\section{Conclusiones}

Este artículo ha tratado de examinar la complejidad que subyace detrás de las políticas de representación y definición identitaria que tienen lugar en el espacio ibérico, y más concretamente en los territorios extremeño y canario. En ambos casos, la presencia del arte contemporáneo portugués se justifica por lazos históricos o supuestamente naturales. Sin embargo, como se ha podido examinar, dicha presencia forma parte de un juego más complejo de políticas culturales. Esa complejidad se deriva de las propias dinámicas espaciales de dichos territorios, que, independientemente de las especificidades que muestren dentro del panorama de la España de las Autonomías, se ven tensionadas en época contemporánea en relación a su 'pertenencia y no pertenencia' a Europa y a la voluntad de pensar su posición postcolonial. Al elaborar una crítica sobre los discursos curatoriales extremeños y canarios ligados a Portugal, el interés principal de este trabajo no consiste, en cualquier caso, en señalar aquellos discursos como inexactos o inadecuados; tampoco se busca valorar su idoneidad en relación a otras construcciones identitarias que surgen en el mismo periodo en el ámbito ibérico. A lo largo de este artículo se ha pretendido, por el contrario, comprender cómo las exposiciones de arte contemporáneo han servido para cimentar políticas culturales y vinculaciones espaciales e identitarias diversas.

Si bien en muchos casos ha sido la presencia del arte latinoamericano lo que ha permitido establecer esa definición de modernidades periféricas y de lecturas alternativas de la colonialidad dentro del territorio español, en este artículo he tratado de mostrar cómo la propia presencia de Portugal sirve para generar una geopoética que, de un modo similar, permite establecer un puente -de nuevo, cuestionable y sujeto a crítica- entre la expansión colonial e imperial ibérica y el presente ‘postcolonial’ (véase Rodríguez y Martínez 2008, 2010). La plasmación en el ámbito expositivo de relaciones ibéricas ofrece un campo de análisis fecundo a la hora de examinar las contradicciones de las políticas culturales 'postcoloniales' españolas. Dichas contradicciones nos obligan a pensar la colonialidad del espacio ibérico no tanto a partir de la individualización de sujetos y grupos migrantes o subalternos; ni tampoco como un elemento relacionado con productos artísticos o literarios 'otros', procedentes de las periferias, sino también, de manera más amplia, en relación a aquellas iniciativas naturales o locales en apariencia poco sospechosas de colonialidad. De acuerdo con estas cuestiones, en este artículo he tratado de situar la producción curatorial española e ibérica en un contexto más amplio, que cuestione en un mismo marco los regionalismos, la marginalización y fragmentación de algunas regiones y la complejidad de las políticas culturales que tensionan la posición ‘atlántica y europea’ ibérica.

\section{Obras citadas}

Aliaga, Juan Vicente, 2005. 'El fondo de la cuestión. Sobre las características del comisariado en el Estado español en las décadas de los 80 y los 90', en Impasse 5. La década equívoca: el trasfondo del arte contemporáneo español en los 90 (Lleida, Ajuntament de Lleida i Centre d'art la Panera), pp. 233-51. 
Appiah, Kwame Anthony, 1991. 'Is the Post- in Postmodernism the Post- in Postcolonial', Critical Inquiry, 17.2: 336-57.

Barker, Emma, 1999. Contemporary Cultures of Display (New Haven, CT: Yale University Press).

Basso Peressut, Luca, Francesca Lanz y Gennaro Postiglione (eds), 2013. European Museums in the 21st Century (Milano, Italia: Politecnico di Milano).

Bhabha, Homi, 1994. The Location of Culture (Nueva York: Routledge).

Britto Jinnorio, Orlando, y Nilo Palenzuela (eds), 2010. Horizontes Insulares (Santa Cruz de Tenerife: Gobierno de Canarias, Sociedad Estatal para la Acción Cultural Exterior (SEACEX)).

Buffery, Helena, Stuart Davis y Kristy Hooper (eds), 2007. Reading Iberia: Theory/ History/ Identity (Oxford: Peter Lang).

CAAM véase Centro Atlántico de Arte Moderno.

Cabañas Bravo, Miguel, 2001. El arte español del siglo XX. Su perspectiva al final del milenio (Madrid: CSIC).

Calafate Ribeiro, Margarida, y Ana Paula Ferreira (coords), 2003. Fantasmas e fantasias imperiais no Imaginário Português Contemporâneo (Porto, Portugal: Campo das Letras).

Centro Atlántico de Arte Moderno (CAAM), s. d. Dossier CAAM. CAAM, retrospectiva” [CAAM, en línea.] Disponible en: http://www.caam.net/es/pdf/historia.pdf [búsqueda realizada el 16 de septiembre de 2016].

Chambers, Iain, Alessandra de Angelis, Celeste Ianniciello, Mariangela Orabona y Michaela Quadraro (eds), 2014. The Postcolonial Museum. The Arts of Memory and the Pressures of History (Farnham, UK: Ashgate).

Carrillo, Jesús, y Ignacio Estrella Noriega (eds), 2004. Desacuerdos: Sobre arte, políticas y esfera pública en el Estado español, 1 (Madrid: Arteleku-Diputación Foral de Gipuzkoa, Museu d’Art Contemporani de Barcelona, UNIA Arte y Pensamiento).

Clara, Fernando, 2006. 'O fim da Europa. Onde a nação acaba e o império começa', en 'Portugal não é um país pequeno'. Contar o Império na Pós-Colonialidade, ed. Manuela Ribeiro Sanches (Lisboa: Cotovia), pp. 271-85.

Crichlow, Michaeline A., y Patricia Northover, 2009. Globalization and the Post-Creole Imagination. Notes on Fleeing the Plantation (Durham, NC: Duke University Press).

De Sousa Santos, Boaventura, 1994. Pela mão de Alice. 0 social e o politico na pós-modernidade (Porto, Portugal: Afrontamento).

-, 2002. 'Between Prospero and Caliban: Colonialism, Postcolonialism, and Inter-Identity', Luso-Brazilian Review, 39.2: 9-43.

Epps, Brad, y Luis Fernández Cifuentes (eds), 2005. Spain beyond Spain. Modernity, Literary History and National Identity (Lewisburg, PA: Bucknell University Press).

Esteban, Iñaki, 2007. El efecto Guggenheim: del espacio basura al ornamento (Barcelona: Anagrama).

Fernandes Dias, Antonio, 2006. 'Pós-colonialismo nas artes visuais, ou talvez não', en 'Portugal não é um país pequeno'. Contar o Império na pós-colonialidade, ed. Manuela Ribeiro Sanches (Lisboa: Cotovia), pp. 317-39.

Franco Domínguez, Antonio, 1995. 'Presentación. Museo Extremeño e Iberoamericano de Arte Contemporáneo', en Museo Extremeño e Iberoamericano de Arte Contemporáneo (Badajoz: MEIAC), pp. 17-39.

Godoy, Francisco, 2011. 'El panóptico extremeño. Voluntades explícitas y problemas implícitos en el proyecto MEIAC', SalonKritik. Disponible en: http://salonkritik.net/10-11/2011/10/el_ panoptico_extremeno_volunta.php [último acceso: 3 de junio de 2015].

Gracia García, Jordi, y Domingo Ródenas de Moya (eds), 2009. Más es más: sociedad y cultura en la España democrática, 1986-2008 (Madrid y Frankfurt: Iberoamericana).

Holo, Shelma Reuben, 1999. Beyond the Prado. Museums and Identity in Democratic Spain (Washington DC: Smithsonian).

Logroño, Miguel, 1995. ‘Geografía del arte. Centro y periferia’, en Museo Extremeño e Iberoamericano de Arte Contemporáneo (Badajoz: MEIAC), pp. 247-57.

Loomba, Ania, 2015. Colonialism/Postcolonialism (Nueva York: Routledge).

Lourenço, Eduardo, 1994. 0 Labirinto da Saudade (Lisboa: Don Quixote).

Maharaj, Sarat, s. d. [2005]. 'Merz-Thinking. Sounding the Documenta Process Between Critique 
and Spectacle', On Curating, 9: 11-19. Disponible en: http://oncurating.org/index.php/ issue-9.html\#.VXv-pkZPUZw [último acceso 13 de junio de 2015].

Monclús Fraga, F. Javier, 2006. Exposiciones internacionales y urbanismo. El proyecto Expo Zaragoza 2008 (Barcelona: Edicions de la Universitat Politècnica de Catalunya).

Mosquera, Gerardo (ed.), 2004. Adiós Identidad (Badajoz: MEIAC).

Njami, Simon, 1999. 'La aventura del CAAM', Atlántica, 24: 22-23.

O’Neill, Paul (ed.), 2007. Curating Subjects (Londres: Open Editions).

-, 2012. The Culture of Curating and the Curating of Culture(s) (Cambridge, MA: MIT Press).

Pérez Isasi, Santiago, 2013. 'Iberian Studies: A State of the Art and Future Perspectives', en Looking at Iberia. A Comparative European Perspective, ed. por Santiago Pérez-Isasi y Ângela Fernandes (Oxford: Peter Lang), pp. 11-27.

Pinto de Almeida, Bernardo, 1995. 'La obra de arte portuguesa en la era de su museificación', en Museo Extremeño e Iberoamericano de Arte Contemporáneo (Badajoz: MEIAC), pp. 175-93.

Ramírez, Juan Antonio, y Jesús Carrillo (eds), 2004. Tendencias del arte, arte de tendencias a principios del siglo XXI (Madrid: Cátedra).

Renau, Lluís del Romero, 2010. 'Dos décadas de urbanismo-espectáculo en España: los grandes eventos como motor de cambio urbano’, Boletín de la Asociación de Geógrafos Españoles, 53: 309-327.

Ribeiro Sanches, Manuela (ed.), 2006. 'Portugal não é um país pequeno'. Contar o Império na pós-colonialidade (Lisboa: Cotovia).

Rodríguez, Ileana, y Josebe Martínez (eds), 2008. Postcolonialidades históricas: (in)visibilidades hispanoamericanas/ colonialismos ibéricos (Barcelona: Anthropos).

- y - (eds), 2010. Estudios transatlánticos postcoloniales I: Narrativas comando, Sistemas mundo, colonialidad, modernidad (Barcelona: Anthropos).

Rosengarten, Ruth, 1998. 'Out of Africa. Um olhar sobre as relações entre a arte contemporânea em Portugal e em África', Belém, 4: 218-37.

Sáez Delgado, Antonio, y Luis Manuel Gaspar (eds), 2010. Suroeste: relaciones literarias y artísticas entre Portugal y España (1890-1936) (Badajoz: MEIAC, Sociedad Estatal de Conmemoraciones Culturales).

Sardica, Miguel, 2013. Ibéria. A relação entre Portugal e Espanha no século XX (Lisboa: Alêtheia).

Tawadros, Gilane, 2005. 'Re-Imagining Europe: Contemporary Art and Ideas in an Era of Globalization', en The Manifesta Decade. Debates on Contemporary Art Exhibitions and Biennials in PostWall Europe, ed. Barbara Vanderlinden y Elena Filipovic (Cambridge, MA: MIT Press), pp. $167-75$.

Vale de Almeida, Miguel, 2000. Um mar da cor da terra. Raça, cultura e política da identidade (Oeiras: Celta).

Vecchi, Roberto, 2013. 'Thinking from Europe about an Iberian "South”: Portugal as a Case Study', en Looking at Iberia. A Comparative European Perspective, ed. Santiago Pérez-Isasi y Ângela Fernandes (Oxford: Peter Lang), pp. 69-87.

Viala, Fabienne, 2014. The Post-Columbus Syndrome. Identities, Cultural Nationalism, and Commemorations in the Caribbean (Londres: Palgrave).

Vilarós, Teresa, 2005. 'Banalidad y biopolítica: la transición española y el nuevo orden mundial', en Desacuerdos: Sobre arte, políticas y esfera pública en el Estado español, 2, ed. Jesús Carrillo, Ignacio Estrella Noriega y Lidia García-Merás (Madrid: Arteleku-Diputación Foral de Gipuzkoa, Museu d'Art Contemporani de Barcelona, UNIA Arte y Pensamiento), pp. 31-56.

Villafranca, Mar, 1998. 'Além da água. Un proyecto transfronterizo Alentejo-Extremadura', Atlántica 20: 122-27.

Whitehead, Christopher, Katherine Lloyd, Susannah Eckersley y Rhiannon Mason (eds), 2015. Museums, Migration and Identity in Europe (Farnham, UK: Ashgate). 
